\title{
Reforma no ensino médico
}

$\mathrm{T}$ ranscrevemos a seguir artigo por nós publicado com o título acima no caderno regional da Folha de São Paulo ("Folha Ribeirão") em 23 de outubro último:

"A sucessão de casos recentes de condutas médicas danosas aos pacientes tem despertado o interesse da sociedade na qualidade da educação médica do país e na sua capacidade de se adaptar às mudanças rápidas da ciência e da própria sociedade. Mesmo se sabendo que o desempenho médico é determinado por muitos fatores além da educação acadêmica, algumas faculdades, movidas por esta pressão externa e, até mais, por insatisfação interna, têm repensado sua forma de ensinar Medicina".

Há quatro anos, a Faculdade de Medicina de Ribeirão Preto (FMRP) concluiu o projeto de reforma do seu currículo médico e iniciou sua implementação. Os principais objetivos conceituais eram a maior integração entre as disciplinas, tanto do ciclo básico como do clínico, a exposição mais precoce e mais intensa do estudante a problemas de saúde na comunidade e a opção por um curso biomédico para formação científica básica. A consecução plena destes objetivos pode ser questionada, pois apenas um em cada cem estudantes tem optado pela Biomedicina, como era previsto, embora sejam inegáveis alguns avanços, como a integração morfofisiológica, clínico-cirúrgica e adulto-infantil em alguns cursos. Entretanto, integração é um conceito mais fácil de ser defendido do que praticado e a do curriculo da FMRP carece da adesão maciça de áreas centrais como a Patologia.

Atualmente, está se discutindo a estruturação do internato, periodo de treinamento em ser viço, que passou de 1 para 2 anos e se inicia já em 1997, sem que a Congregação da Faculdade conseguisse ainda definir seu programa. Entre muitos outros, o ponto mais polêmico é a extensão do treinamento médico que será feito diretamente junto à comunidade, em oposição às enfermarias e ambulatórios do Hospital das Clínicas. A ampliação dos programas existentes, no Centro-Saúde Escola de Monte Alegre, na Vila Lobato e em pequenas comunidades como Cássia dos Coqueiros, esbarra na falta de quadros docentes vocacionados para esta atividade na FMRP e na dificuldade de recrutá-los entre os pós-graduandos, diante da crise financeira da USP.

A reforma ora em curso na FMRP talvez fosse inovadora no início da década de 70, quando foi proposta pelo Centro Acadêmico Rocha Lima e rejeitada. Hoje, um grande número de faculdades do $1^{\circ}$ mundo, incluindo a famosa Harvard, revoluci- onaram seu curriculo médico, transformando-o em 'Ensino Baseado em Problemas" (PBL, Problem Based Learning), em que os estudantes, desde o primeiro dia de aula, são tutorados a resolver casos clínicos reais e, com isto, aprendem toda a ciência básica e clínica, de um modo informal, ativo e agradável. Ao contrário do que possa parecer, a transição para e a coexistência entre os sistemas tradicional e revolucionário são muito dificeis. E possivel que, daqui a 20 anos, estejamos adotando o PBL em nossas escolas médicas, quando todo o ensino estiver sendo feito em realidade virtual..."

O terceiro parágrafo do artigo refletia a preocupação com o novo esquema de internato, cuja grade curricular só veio a ser definida no início de dezembro. Temia-se que a duplicação do período do internato não pudesse ser acomodada nas já concorridas instalações do HCFMRP (na Unidade de Emergência e no Campus da USP), povoadas de pacientes de alta complexidade e de superespecialistas, aparentemente inadequados para o treinamento médico geral dos internos. Temia-se, em particular, pelos novos estágios de Medicina Comunitária, baseados em postos de saúde da periferia, principalmente em áreas sem tradição e sem docentes especializados nesta atividade, como a Clínica Médica e a Cirurgia. Felizmente, nenhuns destes temores se confirmaram, pois os estágios junto à comunidade e ao Centro-Saúde Escola têm contado com a coordenação entusiasmada de docentes e com a execução dedicada de médicos, a maioria pós-graduandos, recrutados para este fim. Nas disciplinas especializadas, pelo menos da Clínica Médica, os internos estão aprendendo a extrair dos casos mais complexos os princípios fundamentais da prática da Medicina.

Vários aspectos da reforma curricular da FMRP foram abordados, de forma direta ou indireta, no Simpósio de Educação Médica publicado neste número. Dois deles merecem comentário especial: a integração entre as disciplinas e a possibilidade de implantação do Ensino Baseado em Problemas (PBL, Problem Based Learning).

Em sua análise crítica da nova estrutura curricular da FMRP, o prof. William Prado, presidente da Comissão de Graduação da Faculdade e um dos exe- 
cutores da reforma, enaltece a "integração de importante fração do conteúdo de Patologia com os das disciplinas do setor clínico" e o fato de que "na fase préclínica, o conteúdo da Patologia referente aos sistemas cardiovascular, respiratório, digestivo, renal e endócrino é oferecido em paralelo aos cursos de Semiologia...". Trata-se de argumento ingenuamente sofismático, pois uma das grandes deficiências desta reforma é exatamente a incapacidade de se integrar o ensino da patologia dos sistemas mencionados acima com o da clínica e cirurgia, estes sim interligados em blocos na nova estrutura. Além disso, o fato da Patologia Especial correr à tarde em paralelo com a Semiologia, além de não promover integração clínico-patológica significativa, tem conseqüências catastróficas para o ensino da propedêutica do adulto e da criança, dado o regime draconiano de avaliação vigente no curso vespertino. Este é um aspecto de poder departamental o qual nem a reforma curricular nem o lamento dos alunos e professores dos cursos propedêuticos lograram abalar. As dificuldades de integração curricular estendem-se por todo o currículo, desde as colchas de retalhos massacrantes dos blocos básicos até disciplinas da Clínica Médica que insistem em manter sua individualidade e atomizar blocos clínicos supostamente integrados.

No Simpósio de Ensino Médico publicado neste número, há dois artigos sobre Problem Based Learning, um escrito por membros da Comissão de Graduação da FMRP e outro por uma tutora do método na Faculdade de Medicina de Springfield, nos EUA. Com amplo apoio institucional, docentes da FMRP, entre os quais me incluo, têm tido oportunidade de tomar contato com experiências de PBL no Brasil e no exterior. A simpática educadora de Springfield, Pamela Moriearty, por exemplo, ministrou um seminário prático sobre esta metodologia a um limitado grupo de docentes e pós-graduandos na FMRP no início de 1996. Este interesse da administração da FMRP por PBL encontra justificativa nas inúmeras vantagens que ele possui sobre o ensino médico tradicional: aprendese de modo realmente integrado, partindo de um caso clínico, utilizando variadas

fontes de informação e o trabalho em grupo, onde o aluno é responsável pelo seu próprio desenvolvimento, preparando-o para a educação continuada e independente no futuro. Seu mérito tal vez mais importante, principalmente para as matérias básicas, é propiciar aprendizado aplicado, estimulante e prazeroso.

Os dois artigos sobre PBL neste Simpósio concluem que a desejável introdução deste método revolucionário de ensino na FMRP deveria começar por sua adoção em segmentos específicos do currículo médico e, uma vez testada sua eficácia, estendê-lo-se-ia ao resto do curso. Embora aparentemente lógica, esta estratégia gradualista implica em que, provavelmente, o $\mathrm{PBL}$, ou qualquer outra forma realmente inovadora de ensino médico, jamais será adotada na FMRP. A simultaneidade do ensino tradicional e do PBL no mesmo currículo não permite nem o desenvolvimento do PBL nem a comparação de suas eficácias e, muito menos, a mobilização da Faculdade para sua implantação.

A própria reforma curricular ora em curso, baseada no esquema 2-2-2 ( $\mathrm{n}^{\circ}$ de anos dos ciclos básico, clínico e internato) e na integração vertical de disciplinas foi adotada mais de 20 anos depois de proposta pelos alunos, quando já havia sido abandonada na maioria dos centros que a implantaram, como a Universidade de Brasília e o Curso Experimental da FMUSP. Uma das suas grandes falhas é a de não se promover integração real de conhecimentos simplesmente ministrando aulas de temas correlatos em períodos próximos, o que, como vimos acima, nem se conseguiu implementar integralmente no atual currículo.

Entre as justificativas para se fazer uma reforma de ensino, mesmo que não seja ideal, ressalta a de predispor a instituição a mudanças mais radicais no futuro. Isto pode não ser verdade em situações como a nossa, em que o ensino de graduação compete, em prioridade, com várias outras atividades docentes e onde a frustração com problemas não resolvidos ou exacerbados pelo currículo recém-implantado cria resistências à reformas futuras. E muito provável que, em 1992, tenhamos perdido uma oportunidade ímpar, que não se repetirá nas próximas décadas, de promover uma reestruturação profunda e realmente significativa no ensino médico da FMRP.

\section{Prof. Dr. Júlio C. Voltarelli}

Editor 